\title{
'Other' gender in India: An Analysis of 2011 Census Data
}

\author{
Chaitali Mandal ${ }^{1}$, Paramita Debnath ${ }^{2}$, Apyayee Sil $^{3}$
}

\begin{abstract}
In spite of a lot of human rights protection given to the 'other-gender' population worldwide, they still have been a deserted community who faces a significant occupational challenge around the world. In India, the other-gender community encompasses persons with a variety of gender identities, forming a culturally unique gender group. Although they have always remained an integral part of the society from the very ancient time, unfortunately, their existence is grappling with abject poverty, illiteracy, hatred, and mockery. Such stigmatisation and segregation from society have left them to compromise with the employment opportunities available. It is important to identify the gap between the other-gender population and general population in the field of literacy and workforce participation. This paper uses the data on othergender published by the Census of India for the first time. According to the Indian Census 2011, there is around 4.9 lakh other-gender population in the country. The data reveal that othergender have lower levels of literacy and labour force participation compared with the general population. Our attempt is here to conceptualise the findings along with some discussion on the data limitations.
\end{abstract}

Keywords: 'Other' gender, literacy, workforce participation, India

\section{Introduction:}

The word Hijra in Hindi refers to a person who appears to have the characteristics of both the genders that are masculine and feminine, identified as the 'other-gender' (transgender) of India, or as individuals 'neither male nor female' (MoCoy, 2014). The 'others' are one of the most neglected social groups of India, and not much research has been carried out in the past on their labour force participation in India. While they are almost deified in some aspects in India and in many other countries by different names, they are very often considered as an object of curiosity, ridicule, exploitation, and abuse (Babbar, 2016).

Gender identity and sexual orientation have always been a concern with the society creating a debate about the legality and human rights (Agrawal, 2016). The right to choose an individual's gender identity is very important to lead their lives with respect, which falls under the ambit of Article 21 of the Indian Constitution. With Constitution determining the right to personal freedom and self-determination, the Supreme Court of India has also observed that the gender

\footnotetext{
${ }^{1}$ Chaitali Mandal, Project Officer, International Institute for Population Sciences, Deonar, Mumbai 400088. Email: chaitali.geo@gmail.com

${ }^{2}$ Paramita Debnath, Senior Research Scholar, International Institute for Population Sciences, Deonar, Mumbai 400088. Email: paramitadebnath21@gmail.com

${ }^{3}$ Apyayee Sil, Senior Research Scholar, International Institute for Population Sciences, Deonar, Mumbai 400088. Email: apyayeesil@yahoo.co.in
} 
to which a person belongs is to be determined by the person concerned (Kumar, 2016). Hence, the Court has given the people of India the right to decide about their gender identity. Earlier, the Census of India did not list the other-gender separately; they were usually counted as men, but later on request, they could be counted as women also. It was thus impossible to estimate with certainty how many other-gender people were there in India. However, the official introduction to the category was given by the census 2011: "In Census 2011, three Codes were provided for recording gender i.e., Male-1, Female-2, and Other-3. In case the respondent wished to record neither ' 1 ' nor '2', the enumerator was instructed to record sex as 'Other' and give code ' 3 '. Thus, the category of 'other' would include not only transgender but also any person who desired to record sex under the category of 'other' (Bhagat, 2015). It is also possible that transgender people might have returned themselves either male or female depending on their choice.

India has achieved significant growth and development in recent decades. The situation has improved for the crucial human development indices such as levels of literacy, employment, and life expectancy. Among these is the other-gender, one of the marginalised and vulnerable groups in the country is straggling on human development indices, including education (Rajesh \& Naved, 2013). The life of other-gender is not same as male and female population; their life is a battle on a day to day basis as there is no acceptance anywhere. They are excluded from society and also ridiculed. They face high levels of stigma in almost every sphere of their life, such as health, schools/colleges, employment, social schemes, and entitlements (Rajkumar, 2016). The other-gender community faces intense discrimination and therefore remains 'invisible', particularly concerning employment. Once they find employment, they face discrimination and exclusion from benefits and entitlements because of their effeminacy (Chettiar, 2015; Bondyopadhyay \& Khan, 2004) and sometimes they are forced to leave and go back to streets to sell their body or beg for a living (Tiwari, 2016). The informal transgender workers are a bivalent collectively in the sense that they are not only exploited economically, but they are also culturally vulnerable because of their transgender identity (Jolly, 2010; Fraser, 1996). Only a few studies compared the other gender population with their counterpart of male and female population; this paper attempts to make a comparison between different gender in the light of literacy and workforce participation and also focused on the specific sector they are working for.

\section{Data and methods:}

Indian Census of 2011, has recognised the other-gender/transgender for the first time while collecting the data. This study uses the 2011 census data on the other-gender population for which a separate Primary Census Abstract (PCA) was released for the first time (RGI, 2011). The PCA on other-gender provides limited information on their socio-economic characteristics such as literacy rate, workers and non-workers population, and child population in the age group of (0-6). It also presents the data separately for other-gender. The census 2011 is the first significant census, which enumerated the other-gender community in India. In the country, as a whole 4,87,803 people were enumerated as other-gender out of which about 3,23,120 and $1,64,683$ live in rural and urban areas, respectively. 
The analysis of the data was performed by using simple rates: 1 . The percentage of 'other' gender population in the States and UTs was calculated from the total 'other' gender population in India; 2. The percentage of literate population (aged 7 years and above) among 'other' was calculated from the 'other' gender population (aged 7 years and above); 3 . The percentage of working population among 'other' gender population is calculated from the total 'other' gender population in India; 4. The percentage of 'other' gender population working in the 'otherworking' sector is also computed from the total 'other' gender population in India; 5. Similarly, the same formulas were used for male and female population from their respective PCA table.

\section{Results:}

\section{Distribution of other-gender}

Figure 1 represent the percentage distribution of the other-gender population in India by states. It is observed that, of the total othergender population of 4.88 lakhs in India, the highest proportion of them is found to be residing in Uttar Pradesh (28.2 percent), followed by Andhra Pradesh (9.0 percent), Maharashtra (8.4 percent) and Bihar (8.4 percent). More than half (54 percent) of India's other-gender population live in these four states only. The percentage of other-gender residing in Puducherry, Goa, Nagaland, Arunachal Pradesh, and Meghalaya is lowest at 0.1 percent each. Among the other-gender residing in rural areas of India, 42.5 percent of them reside in just two

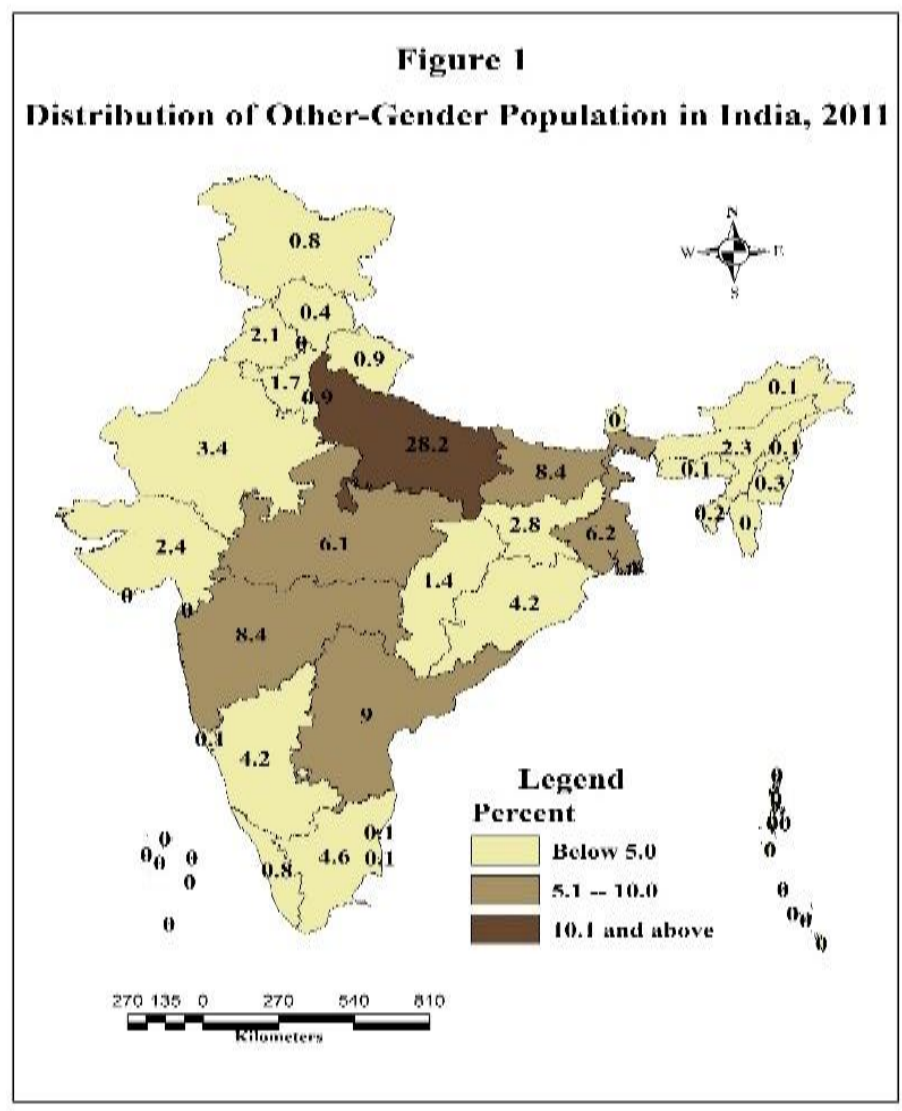
states - Uttar Pradesh and Bihar.

Among the other-gender residing in urban areas of India, more than one-fourth (28.2 percent) of them just live in one state, and more than half of them (54 percent) live in just four states (Uttar Pradesh, Maharashtra, Andhra Pradesh, and Tamil Nadu) of India. The other-gender population in Uttar Pradesh, Bihar, Maharashtra, and Andhra Pradesh could be high due to less stigma attached by the communities to the self-identification as other-gender and better livelihoods for other-gender persons through work opportunities. The data provided by the census are not only crucial for counting purposes; it may be helpful to redefine access to food, healthcare, and early childhood education and to make the systems more inclusive for the othergender population (Venkat, 2016). 


\section{Literacy rate and workforce participation}

Table 1 represent the literacy and workforce participation of male, female and other population by states. It is observed that, the literacy $(80.9 \%)$ rate is considerably high among males than females and 'others' in India. The literacy rate of females (64.6\%) are again higher that 'other'gender $(56.1 \%)$ in India as well as in the states and union territories (except Dadra and Nagar Haveli). It would be interesting to examine the state policies which are leading to the inclusion of the other-gender in education. Along with the other gender, it is very evident that females were also lagging behind males in most of the states in the year 2011. In the majority of the states, the literacy rates of female at states level is similar to the literacy rates of the other gender.

The workforce participation rate (WPR) is also high among males (53.3\%) than their counterparts. However, the workforce participation rate is found to be higher among 'others' $(34 \%)$ than female $(25.5 \%)$ population in India and states. The WPR of females are high in Himachal Pradesh (44.8\%) and low in Delhi (10.6\%); whereas, the WPR of other-gender is Nagaland $(51.8 \%)$ and low in Kerala $(22.7 \%)$.

\section{Working categories}

Table 2 depicts the engagement of population in different working categories in India. The major four categories are: cultivator (CL), agricultural labourer (AL), household worker (HW) and other worker (OT). According to census of India this other workers are engaged in some specific activity but are not cultivators, agricultural labourers, and household industry workers. They include government servants, municipal employees, teachers, factory workers, plantation workers, those in trade, commerce, business, transport, banking, mining, construction, political or social work, priests and entertainment artists, etc. (more specifically includes the service sector).

The data reveals that the population of India is mainly engaged in other work (service sector). Among males, $22 \%$ are cultivators, $16.6 \%$ are agricultural labourer, $2.3 \%$ are household worker, and $41.4 \%$ are other worker. Similarly, among females $15.3 \%$ are cultivators, $20.6 \%$ are agricultural labourer, $3.2 \%$ are household worker, and $20.5 \%$ are other worker. In addition, among other-gender population, $20 \%$ are cultivators, $32.9 \%$ are agricultural labourer, $5.8 \%$ are household worker, and $41.3 \%$ are other worker. Though, the percentage of other-gender in other working category is high as male population, it is not clear in which sector they are currently involved.

\section{Discussion}

The census 2011 was the very 1 st census, which accounts for the other-gender population in India (Venkat, 2016). In the data, a separate table for an "Other" gender has been created, instead of incorporation with traditional census sex categories of Male and Female, which indicates that this population is not yet fully integrated into the census. Incorporation of the other-gender into the total census population would resolve many of the issues of demographic resolution. But, of course, this is easier said than done, and no country has figured out how to count its other-gender population accurately (Venkat, 2016). This is a beginning, and it's good 
that the census could draw out part of the truth and establish that the transgender community exists and that their literacy rate is meagre. Census results say that 55,000 respondents came from parents of the other-gender identifying their children as "others" (Nagarajan, 2014), which was a good sign of acceptance of the other gender.

Also, the data which is available in the Public domain lacks the required demographic resolutions as the state-level findings can only tell us so much. Active inclusion of other-gender individuals in the census involves data on these communities at the district or taluk level. Available information in the 2011 other gender table is not nearly enough to fully understand the different spatial distribution of access and opportunity. However, it has been realised by some research that data at the district or taluk level comes with significant privacy concerns. In many areas, other-gender individuals now face stigma, harassment, and violence due to their gender identity (Chakrapani, 2010). Being able to isolate sensitive data to the district level may not be advisable in many cases, and may even compromise the integrity of other-gender individuals (Venkat, 2016).

The 2011 Other-gender table is also demographically truncated. While traditional Indian census tables display population age information in 10-year increments from $0-80$ and above, the 2011 Other-gender table only contains age-specific counts for the transgender children from 0-6 age group. While this population can help for a particular interest in childcare and health care purposes, the limited amount of age information shared in the public domain limits decision-making for other-gender persons of other ages. Similarly, traditional census occupations cover a range of activities, including agriculture, manufacturing, utilities, trade, public administration, education, etc. The 2011 Other-gender table examines only a limited set of occupations: Cultivators, Agricultural Labourers, Household Industry, and Other (Venkat, 2016). Census 2001 and 2011, shows the percentage distribution of working population in different categories in India, it has been observed that there is an increase of workers in the other workers category and the shift to this category is predominantly from the cultivator category. In the year 2001, separate tables for other-gender was not provided as they were included in the total population, so we can assume that there is an increase in the proportion of other workers in 2011 for the other-gender as well. While cultivators and agricultural labourers dominate in almost all states, the majority of the employed other-gender persons in India report their occupation as "Other" or service sector in the 2011 census, which makes a direct and significant contribution to the GDP, economy, and development of the country. Therefore, a wider variety of professions must be studied to better understand the types of livelihoods accessible to other-gender individuals. Given these challenges, the 2011 Other-gender table is proof that we are capable of collecting this crucial information. As India formulates the methodology for its 2021 census, it leaves scope for the Registrar General and Census Commissioner to continue to expand on the foundations of the 2011 Census for other-gender individuals. We know that state-level information is a great start, but the further spatial and demographic resolution is necessary for planning, resource allocation, and decision-making purposes. 
Over the past few years, the changes in-laws for the transgender community proved that slowly but steadily, the transgender population is on the path of acceptance and being treated as equal citizens (Vahishth, 2017). Some crucial changes in laws made by the government recently made the life more comfortable for transgender community: Tamil Nadu and Kerala were the first two states to introduce transgender welfare policies like counselling, pension for destitute the other-gender, free sex reassignment surgeries, ration cards, self-employment grants, free homes and transit homes by the transgender welfare board (developed by the ministry of social welfare) in the state, which finally gave them free access to free housing programs, sex reassignment surgery (SRS), admission in government with a full scholarship for higher studies, income generation programs, etc. (Chakrapani ,2012;. Vahishth, 2017). In 2014, Supreme Court recognised transgenders as the other-gender and also to help improve their degrading living conditions, Supreme Court of India declared transgender community as an economically backward class in April 2014, to entitle them with reservations and welfare benefits like- skill development, $2 \%$ reservations in government jobs, legal aid, pension and allowances (Dutta, 2014).

\section{Conclusion}

Gender is a ubiquitous social construct that wields power over every individual in our society. The traditional dichotomous gender paradigm is oppressive, especially for the other-gender population whose sense of themselves as gendered people is incongruent with the gender they were assigned at birth. The other-gender individuals are targeted for mistreatment when others attempt to enforce conventional gender boundaries. The social conditions have enabled them to transform their gender identities entirely: to have feminine names, act in feminine ways, and be recognised as other-gender even if this recognition is veiled with prejudice. The rigid gender binary should be eliminated, either by eliminating it or expanding it to include more gender possibilities. We should keep in mind that they are also human beings and should have equal rights like us. Their articulations of "the good life" and of the importance and demands of work are also as valid and revelatory as those of the middle/upper class, formally educated and formally employed collectives. Likewise, their informal employment is valuable and meaningful even if this is not reflected in their minimum daily wage. As the other-gender population is also growing in the country, the creation of more employment for transgender can lead to more income and output, thereby facilitating economic development along with economic growth in the country.

\section{References}

Agrawal, S. (2016). Transgender community-they are neither a sin, nor a choice: An analysis. Indian Social Science Journal, 5(1), 47.

Babbar, S. K. (2016). The socio-legal exploitation of the third gender in India. IOSR J Humanit Soc Sci, 21, 12-8.

Bhagat, R. B. (2015). Census Categories and Gender Construction: Reflections on Indian Censuses. Social Science Spectrum, 1(1), 1-7.

Chakrapani, V. (2010). Hijras/transgender women in India: HIV, human rights and social exclusion. 
Chakrapani, V. (2012). The case of Tamil Nadu transgender welfare board-insights for developing practical models of social protection programs for transgender people in India: Policy brief. UNDP India.

Chettiar, A. (2015). Problems faced by Hijras (male to female transgenders) in Mumbai with reference to their health and harassment by the police. International Journal of Social Science and Humanity, 5(9), 752.

Dutta, A. (2014). Contradictory tendencies: the Supreme Court's NALSA judgment on transgender recognition and rights. J. Indian L. \& Soc'y, 5, 225.

Fraser, N. (2009). Social justice in the age of identity politics. Geographic thought: A praxis perspective, 72-91.

Jolly, S. (2010). Pleasure and Empowerment: Connections and disconnections. Development, 53(2), 227-231.

Khan, S., Bondyopadhyay, A., \& Mulji, K. (2005). From the front line: The impact of social, legal and judicial impediments to sexual health promotion and HIV and AIDS-related care and support for males who have sex with males in Bangladesh and India: A study report. London: Naz Foundation International. Accessed at https://www.eldis.org/document/A32468

Kumar, S. M. (2016). Case comment on National legal Services Authority v. Union of India \& others (air 2014 Sc 1863): a Ray of hope for the LGBT community. BRICS Law Journal, 3(2).

MoCoy, T. (2014). India now recognizes transgender citizen as „Third Gender". Washington Post. Retrieved, 15.

Nagarajan, R (2014) First count of third gender in census: 4.9 lakh. http://timesofindia.indiatimes.com/india/First-count-of-third-gender-in-census-4-9 lakh/articleshow/35741613.cms on 28/12/2016.

Rajesh, \& Naved A. (2013). Approach paper on education and employment opportunities and challenges for transgender: New Delhi: Ministry of Social Justice and Empowerment, Government of India.

Rajkumar. (2016). Education of Transgender in India: Status and Challenges. International Journal of Research in Economics and Social Sciences, 6(11), 15-24.

Registrar General of India (2011) Census of India (2011): Primary Census Abstract, Government of India, New Delhi.

Tiwari, A. (2016). Are workplace welcoming of transgender people in India? Youth ki Awaaz. Retrieved from https://www.youthkiawaaz.com/2016/07/trans-people-in-indianworkplace/

Vahishth, N. (2017). Beyond gender: 5 laws that prove new India is accepting the transgender community. Retrieved from https://www.indiatoday.in/fyi/story/transgeder-lawchanges-transgender-rights-india-transgender-public-toilet-free-choice-970132-201704-07

Venkat, A. (2016). Counting the other-gender: Lessons from 2011 for an inclusive 2021 Indian Census. Retrieved from https://medium.com/@ashvenkat/counting-the-othergender-aafe7e858e07 
Table 1: Literacy rate and workforce participation rate by sex in India, 2011.

\begin{tabular}{|l|rrr|rrr|}
\hline \multirow{2}{*}{ States/UTs/India } & \multicolumn{3}{|c|}{ Literacy } & \multicolumn{3}{c|}{ Workforce } \\
\cline { 2 - 7 } & Male & Female & Other & Male & Female & Other \\
\hline Jammu \& Kashmir & 76.8 & 56.4 & 49.3 & 48.1 & 19.1 & 33.3 \\
Himachal Pradesh & 89.5 & 75.9 & 62.1 & 58.7 & 44.8 & 49.3 \\
Punjab & 80.4 & 70.7 & 59.7 & 55.2 & 13.9 & 32.1 \\
Chandigarh & 90.0 & 81.2 & 72.2 & 56.5 & 16.0 & 37.3 \\
Uttarakhand & 87.4 & 70.0 & 62.7 & 49.7 & 26.7 & 34.9 \\
Haryana & 84.1 & 65.9 & 62.1 & 50.4 & 17.8 & 29.9 \\
Delhi & 90.9 & 80.8 & 63.0 & 53.0 & 10.6 & 40.1 \\
Rajasthan & 79.2 & 52.1 & 48.3 & 51.5 & 35.1 & 37.1 \\
Uttar Pradesh & 77.3 & 57.2 & 55.8 & 47.7 & 16.7 & 27.7 \\
Bihar & 71.2 & 51.5 & 44.3 & 46.5 & 19.1 & 32.5 \\
Sikkim & 86.6 & 75.6 & 65.2 & 60.2 & 39.6 & 51.6 \\
Arunachal Pradesh & 72.6 & 57.7 & 52.2 & 49.1 & 35.4 & 48.5 \\
Nagaland & 82.8 & 76.1 & 70.7 & 53.4 & 44.7 & 51.8 \\
Manipur & 83.6 & 70.3 & 67.5 & 51.4 & 39.9 & 48.7 \\
Mizoram & 93.3 & 89.3 & 87.1 & 52.4 & 36.2 & 47.0 \\
Tripura & 91.5 & 82.7 & 71.2 & 55.8 & 23.6 & 36.9 \\
Meghalaya & 76.0 & 72.9 & 57.4 & 47.2 & 32.7 & 42.7 \\
Assam & 77.8 & 66.3 & 53.7 & 53.6 & 22.5 & 35.8 \\
West Bengal & 81.7 & 70.5 & 58.8 & 57.1 & 18.1 & 32.5 \\
Jharkhand & 76.8 & 55.4 & 47.6 & 49.8 & 29.1 & 36.3 \\
Odisha & 81.6 & 64.0 & 54.3 & 56.1 & 27.2 & 31.8 \\
Chhattisgarh & 80.3 & 60.2 & 51.4 & 55.6 & 39.7 & 40.1 \\
Madhya Pradesh & 78.7 & 59.2 & 53.0 & 53.6 & 32.6 & 37.6 \\
Gujarat & 85.8 & 69.7 & 62.8 & 57.2 & 23.4 & 36.0 \\
Daman \& Diu & 91.5 & 79.5 & 75.5 & 71.5 & 14.9 & 35.6 \\
Dadra \& Nagar Haveli & 85.2 & 64.3 & 73.7 & 61.6 & 25.3 & 32.6 \\
Maharashtra & 88.4 & 75.9 & 67.6 & 56.0 & 31.1 & 37.9 \\
Andhra Pradesh & 74.9 & 59.1 & 53.3 & 57.0 & 36.2 & 39.7 \\
Karnataka & 82.5 & 68.1 & 58.8 & 59.0 & 31.9 & 39.8 \\
Goa & 92.6 & 84.7 & 73.9 & 56.8 & 21.9 & 34.2 \\
Lakshadweep & 95.6 & 87.9 & 50.0 & 46.2 & 11.0 & 0.0 \\
Kerala & 96.1 & 92.1 & 84.6 & 52.7 & 18.2 & 22.7 \\
Tamil Nadu & 86.8 & 73.4 & 57.8 & 59.3 & 31.8 & 43.7 \\
Puducherry & 91.3 & 80.7 & 60.6 & 54.4 & 17.6 & 30.2 \\
Andaman \& Nicobar Islands & 90.3 & 82.4 & 73.8 & 59.6 & 17.8 & 23.4 \\
\hline India & $\mathbf{8 0 . 9}$ & $\mathbf{6 4 . 6}$ & $\mathbf{5 6 . 1}$ & $\mathbf{5 3 . 3}$ & $\mathbf{2 5 . 5}$ & $\mathbf{3 4 . 0}$ \\
\hline
\end{tabular}


Table 2: Percentage of workers in different working categories by sex in India, 2011.

\begin{tabular}{|c|c|c|c|c|c|c|c|c|c|c|c|c|}
\hline \multirow{2}{*}{ State/UT's/India } & \multicolumn{3}{|c|}{ CL } & \multicolumn{3}{|c|}{$\mathbf{A L}$} & \multicolumn{3}{|c|}{ HW } & \multicolumn{3}{|c|}{ OT } \\
\hline & Male & Female & Other & Male & Female & Other & Male & Female & Other & Male & Female & Other \\
\hline Jammu \& Kashmir & 15.2 & 7.1 & 22.5 & 4.5 & 1.5 & 12.8 & 1.8 & 1.8 & 5.6 & 50.6 & 19.6 & 59.1 \\
\hline Himachal Pradesh & 25.2 & 26.7 & 64.7 & 2.3 & 1.5 & 4.7 & 1.2 & 0.5 & 2.2 & 41.8 & 12.4 & 28.4 \\
\hline Punjab & 21.0 & 6.1 & 12.3 & 12.6 & 8.4 & 13.7 & 2.7 & 4.6 & 5.1 & 53.8 & 45.8 & 68.9 \\
\hline Chandigarh & 0.6 & 0.3 & 0.0 & 0.4 & 0.3 & 0.0 & 1.0 & 1.2 & 0.0 & 94.7 & 88.6 & 100.0 \\
\hline Uttarakhand & 21.4 & 37.9 & 38.6 & 7.7 & 3.9 & 10.4 & 2.1 & 1.7 & 4.4 & 50.0 & 17.1 & 46.6 \\
\hline Haryana & 24.0 & 15.7 & 16.7 & 10.6 & 8.2 & 13.8 & 2.3 & 2.0 & 4.0 & 49.2 & 28.9 & 65.5 \\
\hline NCT of Delhi & 0.5 & 0.4 & 0.2 & 0.5 & 0.7 & 0.4 & 3.1 & 2.8 & 2.7 & 91.7 & 86.3 & 96.7 \\
\hline Rajasthan & 34.8 & 30.0 & 40.8 & 7.0 & 7.9 & 20.0 & 2.0 & 1.2 & 3.1 & 39.5 & 11.0 & 36.1 \\
\hline Uttar Pradesh & 27.5 & 11.6 & 23.4 & 15.6 & 12.4 & 30.0 & 3.3 & 4.6 & 8.8 & 28.6 & 16.6 & 37.8 \\
\hline Bihar & 18.6 & 7.6 & 17.2 & 29.2 & 22.8 & 52.8 & 1.9 & 3.1 & 6.1 & 18.7 & 9.6 & 23.9 \\
\hline Sikkim & 26.0 & 28.2 & 47.7 & 3.7 & 3.9 & 13.8 & 1.1 & 0.7 & 1.5 & 51.8 & 28.6 & 36.9 \\
\hline Arunachal Pradesh & 37.1 & 49.8 & 36.3 & 3.4 & 3.5 & 11.7 & 0.8 & 0.8 & 2.1 & 44.7 & 20.7 & 50.0 \\
\hline Nagaland & 38.0 & 49.7 & 60.7 & 2.4 & 2.3 & 7.3 & 0.9 & 1.1 & 1.5 & 39.5 & 17.0 & 30.6 \\
\hline Manipur & 38.0 & 32.8 & 45.3 & 3.3 & 3.7 & 8.6 & 1.9 & 5.6 & 5.2 & 40.0 & 21.3 & 41.0 \\
\hline Mizoram & 41.8 & 41.3 & 38.5 & 5.7 & 5.0 & 12.8 & 1.1 & 1.2 & 2.6 & 42.0 & 29.9 & 46.2 \\
\hline Tripura & 20.1 & 8.6 & 15.6 & 15.0 & 10.6 & 24.4 & 1.2 & 1.5 & 4.6 & 48.6 & 23.8 & 55.4 \\
\hline Meghalaya & 34.6 & 34.8 & 53.7 & 10.0 & 9.2 & 18.7 & 0.9 & 1.1 & 2.6 & 37.6 & 24.7 & 25.0 \\
\hline Assam & 31.6 & 12.8 & 27.4 & 8.3 & 5.8 & 17.9 & 1.7 & 2.8 & 7.0 & 40.8 & 26.8 & 47.7 \\
\hline West Bengal & 14.7 & 3.3 & 9.9 & 18.5 & 11.5 & 24.1 & 3.3 & 8.1 & 8.7 & 44.6 & 27.0 & 57.3 \\
\hline Jharkhand & 17.1 & 11.9 & 26.9 & 9.8 & 8.8 & 39.1 & 1.7 & 2.3 & 4.9 & 33.5 & 10.9 & 29.2 \\
\hline Odisha & 24.6 & 6.3 & 15.2 & 14.7 & 11.9 & 44.8 & 2.6 & 2.2 & 5.9 & 32.0 & 13.4 & 34.1 \\
\hline Chhattisgarh & 28.8 & 19.4 & 25.6 & 19.5 & 22.1 & 48.3 & 1.3 & 0.9 & 2.0 & 28.8 & 10.0 & 24.0 \\
\hline Madhya Pradesh & 30.0 & 19.0 & 24.2 & 20.0 & 22.8 & 41.1 & 2.0 & 2.2 & 4.1 & 29.3 & 11.5 & 30.6 \\
\hline Gujarat & 22.6 & 9.9 & 15.0 & 16.7 & 21.9 & 26.1 & 1.0 & 1.0 & 1.8 & 51.7 & 23.2 & 57.1 \\
\hline Daman \& Diu & 1.2 & 2.5 & 9.5 & 0.3 & 1.6 & 0.0 & 0.3 & 0.6 & 0.0 & 95.6 & 80.7 & 90.5 \\
\hline Dadra \& Nagar Haveli & 13.8 & 16.4 & 35.7 & 2.6 & 8.1 & 7.1 & 1.0 & 1.1 & 0.0 & 74.1 & 30.3 & 57.1 \\
\hline Maharashtra & 22.0 & 25.6 & 22.1 & 17.9 & 31.1 & 30.6 & 1.9 & 2.3 & 3.5 & 50.1 & 23.0 & 43.7 \\
\hline Andhra Pradesh & 17.3 & 12.5 & 12.3 & 28.1 & 42.1 & 45.5 & 2.3 & 4.0 & 5.5 & 41.1 & 17.3 & 36.7 \\
\hline Karnataka & 25.0 & 15.3 & 17.2 & 14.3 & 26.1 & 29.8 & 1.9 & 3.6 & 4.0 & 48.3 & 28.4 & 49.0 \\
\hline Goa & 3.5 & 5.8 & 8.8 & 1.6 & 2.7 & 9.6 & 1.9 & 1.8 & 2.2 & 78.1 & 65.2 & 79.4 \\
\hline Lakshadweep & 0.0 & 0.0 & 0.0 & 0.0 & 0.0 & 0.0 & 0.4 & 0.9 & 0.0 & 59.2 & 47.6 & 0.0 \\
\hline Kerala & 5.5 & 2.5 & 4.4 & 7.4 & 9.2 & 14.7 & 1.6 & 2.1 & 2.7 & 70.4 & 54.1 & 78.2 \\
\hline Tamil Nadu & 11.7 & 11.7 & 9.6 & 17.8 & 29.9 & 35.4 & 2.4 & 5.3 & 5.0 & 56.6 & 31.5 & 50.0 \\
\hline Puducherry & 2.8 & 1.4 & 1.3 & 10.0 & 15.3 & 21.1 & 1.1 & 2.5 & 2.6 & 78.2 & 64.0 & 75.0 \\
\hline Andaman \& Nicobar Islands & 8.9 & 6.9 & 0.0 & 1.9 & 1.1 & 0.0 & 0.8 & 1.3 & 9.1 & 74.0 & 61.1 & 90.9 \\
\hline India & 22.0 & 15.3 & 20.0 & 16.6 & 20.6 & 32.9 & 2.3 & 3.2 & 5.8 & 41.4 & 20.5 & 41.3 \\
\hline
\end{tabular}

